\title{
Body Composition and Somatotype in Elite Handball Players
}

Received 23 $3^{\text {rd }}$ August 2019 Accepted $16^{\text {th }}$ October 2019 www.ijpefs.com

\author{
Pantović Marko a, *, Joksimović Marko b, Brkić Boris a, Gladysheva Anna c, \\ Karišik Siniša ${ }^{b}$ and Alejandro Martínez-Rodríguez ${ }^{\mathrm{d}}$
}

Abstract: As the main objective, this research work had to compare pre and post complex training effects on body composition in elite handball players in the Spanish $2^{\text {nd }}$ Division. Eleven players were included in the study. Six of them formed an experimental group, and 5 of them the control group. They have undergone the complex training session which was done once a week. The following parameters were analyzed: BMI (Body Mass Index), somatotype, FM (Fat Mass), MM (Muscle mass), RM (Residual Mass), WHR (Waist to Hip Ratio), BM (Bone Mass). The results have shown that there was a not statistically significant difference after the 6 - week program neither in body composition and somatotypes. Since this program did not have a big influence on body composition we could say that complex training influences body composition should be further researched.

Key Words: Handball, Complex training, Body composition, Performance, Somatotypes
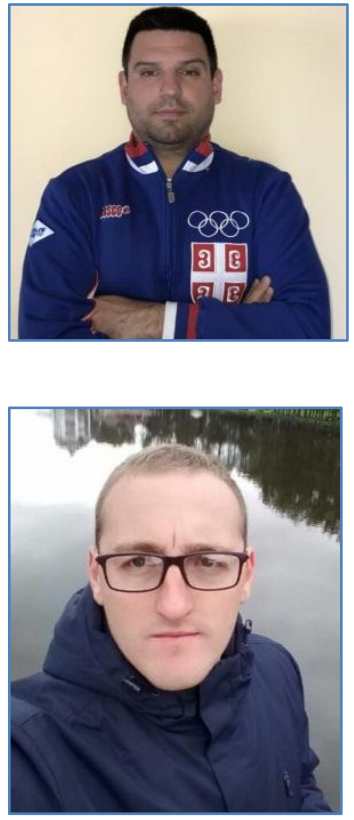

Marko Pantović has a master's in high-performance sport as well as in physical education. He is certified by NSCA (CSCS) and currently doing his PhD in sports science at the University of Belgrade.

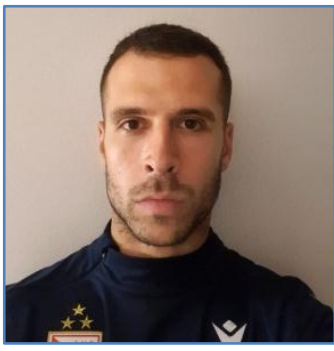

Brkić Boris has done MSc physical education and sport, also he is PhD students of the Faculty of Sport and Physical Education, University of Belgrade. His research interests focus on Strength and Conditioning research in sport

Joksimović Marko completed MSc studies at the Faculty of Physical Education and Sports, University of East Sarajevo. His research interests focus on Soccer, Motor skills, Physical education, Exercise physiology, sports and rehabilitation science, fitness training.

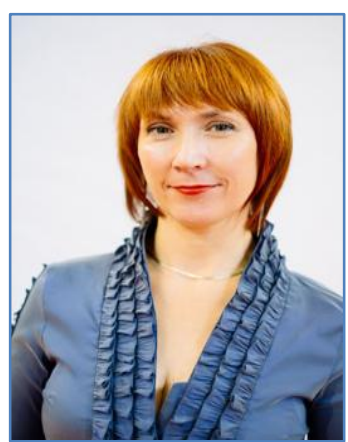

Gladysheva Anna is currently a head of the Department of physical education at Novosibirsk state agrarian University. Her research interests include several areas: the development and evaluation of professional competence of students of physical culture and 
sports areas, the use of digital techniques in the practice of physical culture and sports, the study of the bio-impedance method, influence of different training methods on the health and level of fitness of the various categories of the population.

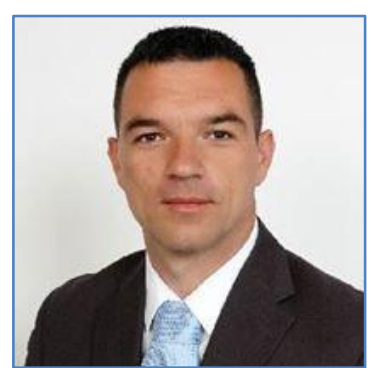

Karišik Siniša PhD is an associate professor at the Faculty of Physical Education and Sports, University of East Sarajevo. He also served as the Technical Director of the Special Winter Olympics in $\mathrm{BiH}$, organized by the Union of Associations for Assistance to Mentally Disabled Persons in Republika Srpska in 2006. His research interests focus on handball, motor skills

\section{Introduction}

Handball is a sport that is played in many European countries [1]. Handball is a sport very similar to water polo, a lot of coaches call water polo "handball in water". It is one of the most physically demanding sports games, so the previous studies have proved handball to be a very complex sports activity. This sport game consists of so many pulling of players dresses (considering this being contact sport), jumps, changes of directions, short sprints, etc. Throwing the ball at high speed seems to be a very important factor in handball players [2]. So, there are five motor dimensions in handball, such as: throwing strength, accuracy, speed of movement with the ball, ball handling, and speed of movement without the ball, and those motor elements have been recognized by several authors [3]. Considering that several motor elements in handball have been confirmed by several authors, the next stage would be to take into account which are the tests and measurements procedures needed to be done in handball players. With no regard for sport, when we wish to improve an athlete's performance execution, we need to start with the anthropometric measurements. These measurements supply a lot of information to us concerning body composition for athletes in almost all competitive sports [4]. There are a few reasons why testing is important for relevant coaches, sports scientists, doctors, etc. The most important reasons are identifying weaknesses, monitoring progress, providing feedback information, educating coaches and sportsmen, and predicting performance potentials. Yet, one of the most significant tests which should be executed in all stages of sportsmen are anthropometry. People responsible for this part of sportsmen's performance usually execute the anthropometric measurements of their sportsmen at the very start of preparation season. The most common procedures being performed are circumferences, skin folds, girths, limb breadths. Anthropometry, like any other area of scientific measurement, depends upon keeping the particular requirements involved in the standards of measurements as they are determined by international standards bodies [5].

There are many scientific studies written about morphological optimization in sport. From another point of view, there are very few studies that have been written on morphological optimization concerning different playing positions. Inseparably, we do know that handball players are to possess some physiological and physical features and there is a certain number of scientific studies that have shown that handball players vary, between playing positions in terms of body composition [3]. Considering that there are four playing positions (backcourt players, pivots, wings, goalkeepers), we can notice that there are significant differences between the players' positions in handball. Wings have shown a tendency to vary from any other position, in particular from pivots $[6,7]$.

This study aimed to compare pre and post effects of complex training on body composition 


\section{Pantović Marko et al.,/2019}

variables such as somatotype, fat mass, muscle mass, recently shown that DXA, previously DEXA (Dualbone mass, residual mass, body mass index and waist energyy X-Ray absorptiometry) is considered as a to hip ratio in elite handball players.

\section{Material and Methods}

\subsection{Sample}

Eleven handball players participated in the study. The handball team Elche (from Elche) is playing in the Second Spanish division. Six of them constituted the experimental group and the other five players consisted of a control group. The experimental one (6 participants) was aged $25.33 \pm$ 4.45 , height $180.35 \pm 5.14 \mathrm{~cm}$ and weighted $84.98 \pm$ 7.32 kgs. The control group (5 participants) was aged $25.20 \pm 8.10$, height $183.66 \pm 6.16 \mathrm{~cm}$ and weighted $81.56 \pm 6.47$ kgs. Goalkeepers have been included in the study. All the participants voluntarily agreed to participate in this study. The procedures were by legal requirements and Declaration of Helsinki for Research in Human Beings and were approved by UCAM (Universidad Catolica de Murcia) Ethical Committee.

\subsection{Instruments}

Anthropometric assessment: for measuring weight scale Tanita BC-100 test (Tokyo, Japan) was used with an accuracy of $\pm 0.1 \mathrm{~g}$. For obtaining muscle size, a tape measure was used, with an accuracy of $\pm 1 \mathrm{~mm}$. The body mass index was calculated using the formula weight / height ${ }^{2}$, and grouped according to the WHO classification on BMI $<18.5 \mathrm{~kg} / \mathrm{m} 2$ : underweight; 18.5 to $24.99 \mathrm{~kg} / \mathrm{m} 2$ : normal; 25 to $29.99 \mathrm{~kg} / \mathrm{m} 2$ : overweight, and $\geq 30$ $\mathrm{kg} / \mathrm{m} 2$ : obesity [8]. Regarding the anthropometric measurement, the methodology used the anthropometry restricted profile [9] and ISAK 1 (International Society for the Advancement of Kinanthropometry). Skinfolds, perimeters and diameters were measured with a caliper, a measuring tape and Pachymeter (Holtain, Crymych, UK). The methodology was done by 1 antrpometrist accredited by ISAK with a measure of the technical error of measurement (TEM) of $0.76 \%$ for the folds and $0.12 \%$ for the rest of ISAK accreditation parameters $(<7.5 \%$ folds and $<1.5$ for all other measures). It is important to notice that it has been gold standard in measuring variables such as fat mass, bone mass, muscle mass, etc. [10]. The measurements were done in the evenings on the handball field. All the subjects were introduced to all test procedures. Warming up part was done on the bicycle ergometer and lasted for 10 minutes, joint mobility exercises and ballistic stretching were included as well. After the warming, up part, the subjects have done 3 exercises in which they performed heavy strength exercises with high loads being immediately followed by plyometric exercises. The exercises have been performed in the following order: squats ( $3 \times 5$ 80\%RM) plus CMJ (Counter Movement Jump), split squat $(3 \times 520 \mathrm{~kg})$ plus jumping lunge $(3 \times 5)$, horizontal leg press $(3 \times 5$ $80 \% \mathrm{RM})$ plus drop Jump $(3 \times 5)$, bench press $(3 \times 5$ $80 \% \mathrm{RM}$ ) plus frontal medicine ball launches $5 \mathrm{~kg}$ $(3 \times 5)$, push-ups $(3 \times 5)$ plus floor above the head medicine ball launches $5 \mathrm{~kg}(3 \times 5)$. Cooling down part took 5 minutes on a bicycle ergometer at low intensity and passive stretching exercises.

\subsection{Variables}

The following dependent variables have been chosen for the study: weight, height, BMI (Body Mass Index), fat mass, bone mass, muscle and residual mass, WHR (Waist to Hip Ratio), and somatotype (ectomorphy, mesomorphy and endomorphy). Also, variables such as skinfolds, perimeters and diameters were used to calculate fat mass, muscle mass, bone and residual mass as well as a somatotype.

\subsection{Variables related to body composition calculation}

As mentioned before, variables such as bone mass, fat mass, residual mass, muscle mass and somatotype were calculated through some of the following equations:

Bone mass (BM) - Rocha's equation: Bone mass $(\mathrm{kg})=3,02 *[\mathrm{Ht} 2 * \mathrm{DM} * \mathrm{DF} * 400] 0,712$ where: DM presents wrist diameter, Ht presents height (squared) and DF presents femur dimater. 


\section{Pantović Marko et al.,/2019}

Fat mass (FM) - 4 - site Skinfold equation: FM (\%) = (0.29288 x sum of skinfolds) - (0.0005 x square of the sum of skinfolds $)+(0.15845 \mathrm{x}$ age $)-5.76377$, where the skinfold sites (measured in $\mathrm{mm}$ ). The following skinfold sites were used: abdominal, triceps, suprailiac and thigh. Muscle mass (MM) Lee's equation: $\mathrm{MM}(\mathrm{kg})=\mathrm{Htm}(0.244 \times \mathrm{BM})+(7.8 \times$ $\mathrm{Ht})+(6.6 \times$ gender $)-(0.098 \times$ age $)+($ ethnicity 3.3) where: MM presents muscle mass and $\mathrm{Htm}$ presents height in meters. Residual mass (RM) was calculated through the following equation: $\mathrm{RM}(\mathrm{Kg})$ $=$ Weight * 24.1/100. BMI (Body Mass Index): weight (kg) / [height (m)] ${ }^{2}$. WHR (Waist to Hip Ratio): Waist circumference / Hip circumference.

Somatotypes were calculated by the following equations:

Endomorphy $=-0.7182+0.1451(\mathrm{X})-0.00068(\mathrm{X}$ squared) +0.0000014 (X cubic) Where: $X=$ (sum of triceps, subscapular and supraspinal skinfolds) multiplied by (170.18 / height in cm). Mesomorphy = $0.858 \times$ humerus breadth $+0.601 \times$ femur breadth + $0.188 \times$ corrected arm girth $+0.161 \times$ corrected calf girth - height $0.131+4.5$. Ectomorphy $=0.463 \mathrm{HWR}$ 17.63, where: HWR presents Height - Weight ratio.

\subsection{Intervention}

The main purpose of this research was to assess and analyze whether there is a difference in body composition after the 6 - week program under the influence of complex training. The players have undergone the 6 - week complex training program. The study began in early January, just after the vacation in which the players had a load of $70 \%$ of overall fitness and between 0\%-30\% physical preparation specified. The program finished after 6 weeks of intervention in which the experimental group performed a complex training protocol and the control group only performed the technical and tactical components that the coach had already planned before. The experimental group performed a complex protocol training once a week for 6 weeks. The control group performed no training protocol except the technical-tactical elements. Warm-up parts were done on the bicycle ergometer and lasted for 10 minutes, the same refers to joint mobility exercises and ballistic stretching. After the warm-up part, the subjects have done 3 exercises where they performed heavy strength exercises with high loads which were immediately followed by plyometric exercises. The exercises have been performed in the following order: squats $3 \times 5$ 80\%RM) plus CMJ (Counter Movement Jump), split squat $(3 \times 520 \mathrm{~kg})$ plus jumping lunge $(3 \times 5)$, horizontal leg press ( $3 \times 5$ 80\%RM) plus drop jump (3x5), bench press $(3 \times 580 \% \mathrm{RM})$ plus frontal medicine ball launches $5 \mathrm{~kg}(3 \times 5)$, push-ups $(3 \times 5)$, plus floor above the head, medicine ball launches 5 $\mathrm{kg}(3 \times 5)$. Cooling down part took 5 minutes on a bicycle ergometer at low intensity and passive stretching exercises.

\subsection{Statistical analysis}

Data analysis was performed using SPSS of the statistical package (Statistical Package for the Social Sciences). Techniques used were descriptive statistics describing each of the measured variables, arithmetic mean; median, mode, scope and vibrational width (Min-Max). In order to examine whether there are differences in body composition measured parameters between the control and experimental groups the Man - Whitney test was used, which represents the non-parametric alternative to the t-test for independent samples, while for determining the difference between the examined parameters before and after treatment in experimental and in the control group by means of Wilcoxon rank test or the Wilcoxon test of equivalent couples who represents the non-parametric alternative to the t-test repeated measurements. P value $<0,05$ was considered statistical difference.

\section{Results}

The study included 11 patients, 6 experimental and 5 in the control group. The age of respondents ranged from 18 to 39 years of age, and the average age of respondents was 25 years. For all measured variables descriptive indicators were calculated: the arithmetic mean, median, mode, range, the minimum and maximum. The results are shown in Table 1. Height, age of respondents, and 
Pantović Marko et al.,/2019

somatotype (endomorfia, mezomorfia ectomorphy) have remained identical during the period of the study and therefore cannot show measurement results after treatment (These results will be shown in the Figures 1(a-d) Reviewing the table of descriptive characteristics of the variables was noted that there had not been many changes after 6 week treatment. Table 1 presents the descriptive indicators for the experimental and control groups.

Table 1. Descriptive statistics for measured variables for the experimental and control grou]

\begin{tabular}{|c|c|c|c|c|c|c|}
\hline \multirow[b]{2}{*}{ Height (Cm) } & \multicolumn{3}{|c|}{ Experimental } & \multicolumn{3}{|c|}{ Control } \\
\hline & $\begin{array}{l}\text { Mean } \\
180.17\end{array}$ & $\begin{array}{l}\text { Median } \\
181.00\end{array}$ & $\begin{array}{l}\text { Mode } \\
181.00\end{array}$ & $\begin{array}{c}\text { Mean } \\
183.40\end{array}$ & $\begin{array}{l}\text { Median } \\
183.00\end{array}$ & $\begin{array}{l}\text { Mode } \\
177.00^{\mathrm{b}}\end{array}$ \\
\hline Endomorfia & 2.72 & 2.75 & $1.60^{\mathrm{b}}$ & 2.62 & 2.80 & $1.98^{\mathrm{b}}$ \\
\hline Mesomorfia & 6.26 & 6.38 & $4.90^{\mathrm{b}}$ & 5.43 & 5.20 & 6.10 \\
\hline Ectomorfia & 1.46 & 1.34 & $.60^{\mathrm{b}}$ & 2.36 & 2.19 & $1.90^{\mathrm{b}}$ \\
\hline Weight (Kg) & 85.30 & 83.90 & $74.90^{\mathrm{b}}$ & 81.68 & 80.50 & $76.50^{\mathrm{b}}$ \\
\hline $\begin{array}{c}\text { Weight (Kg) } \\
\text { Post }\end{array}$ & 84.95 & 83.30 & $74.50^{\mathrm{b}}$ & 81.58 & 80.50 & $76.50^{\mathrm{b}}$ \\
\hline $\begin{array}{c}\text { Waist } \\
\text { minimum } \\
(\mathrm{Cm})\end{array}$ & 84.67 & 85.45 & $77.50^{\mathrm{b}}$ & 84.07 & 83.60 & $78.95^{b}$ \\
\hline $\begin{array}{c}\text { Waist } \\
\text { minimum } \\
\text { (Cm) Post }\end{array}$ & 84.67 & 85.45 & $77.50^{\mathrm{b}}$ & 84.07 & 83.60 & $78.95^{b}$ \\
\hline $\begin{array}{c}\text { Hip } \\
\text { maximum } \\
(\mathrm{Cm})\end{array}$ & 100.08 & 100.45 & $92.60^{\mathrm{b}}$ & 98.18 & 96.40 & $93.80^{\mathrm{b}}$ \\
\hline $\begin{array}{l}\text { Hip } \\
\text { maximum } \\
\text { (Cm) Post }\end{array}$ & 100.08 & 100.45 & $92.60^{\mathrm{b}}$ & 98.18 & 96.40 & $93.80^{\mathrm{b}}$ \\
\hline MM & 49.33 & 49.30 & $44.50^{\mathrm{b}}$ & 48.74 & 49.24 & $43.70^{\mathrm{b}}$ \\
\hline MM Post & 49.18 & 49.00 & $44.50^{\mathrm{b}}$ & 48.71 & 48.99 & $43.80^{\mathrm{b}}$ \\
\hline $\mathbf{B M}$ & 12.83 & 13.20 & $11.00^{\mathrm{b}}$ & 13.33 & 12.93 & $11.80^{\mathrm{b}}$ \\
\hline BM Post & 12.78 & 13.00 & $11.00^{\mathrm{b}}$ & 13.25 & 12.93 & $11.80^{\mathrm{b}}$ \\
\hline $\begin{array}{c}\text { WHR } \\
\text { WHR Post }\end{array}$ & $\begin{array}{l}0.83 \\
0.87\end{array}$ & $\begin{array}{l}0.80 \\
0.90\end{array}$ & $\begin{array}{l}0.80 \\
0.90\end{array}$ & $\begin{array}{l}0.85 \\
0.85\end{array}$ & $\begin{array}{l}0.87 \\
0.87\end{array}$ & $\begin{array}{l}0.80 \\
0.80\end{array}$ \\
\hline BMI & 26.26 & 26.80 & $23.40^{\mathrm{b}}$ & 24.26 & 24.51 & $23.02^{\mathrm{b}}$ \\
\hline BMI Post & 26.15 & 26.68 & $23.25^{b}$ & 24.23 & 24.46 & $23.02^{b}$ \\
\hline $\mathbf{R M}$ & 20.57 & 20.20 & $18.10^{\mathrm{b}}$ & 19.68 & 19.40 & $18.40^{\mathrm{b}}$ \\
\hline RM Post & 20.48 & 20.05 & $17.95^{b}$ & 19.67 & 19.40 & $18.40^{\mathrm{b}}$ \\
\hline $\mathbf{B F}$ & 9.90 & 9.60 & $8.10^{\mathrm{b}}$ & 10.21 & 10.00 & $7.36^{b}$ \\
\hline BF Post & 9.36 & 9.62 & 10.10 & 10.44 & 10.00 & $7.62^{b}$ \\
\hline
\end{tabular}


Pantović Marko et al.,/2019

Table 2. Values of Man - Whitney test and its importance.

\begin{tabular}{|c|c|c|c|c|c|c|c|c|c|c|c|c|c|c|c|c|c|c|c|c|c|c|}
\hline & \multirow{2}{*}{$\begin{array}{l}\text { Heig } \\
\mathrm{ht} \\
(\mathrm{Cm})\end{array}$} & \multirow[t]{2}{*}{$\begin{array}{l}\text { Endomo } \\
\text { rfia }\end{array}$} & \multirow[t]{2}{*}{$\begin{array}{l}\text { Mesomo } \\
\text { rfia }\end{array}$} & \multirow[t]{2}{*}{$\begin{array}{l}\text { Ectomo } \\
\text { rfia }\end{array}$} & \multicolumn{2}{|c|}{$\begin{array}{l}\text { Weight } \\
\text { (Kg) }\end{array}$} & \multicolumn{2}{|c|}{$\begin{array}{l}\text { Waist min. } \\
(\mathrm{Cm})\end{array}$} & \multicolumn{2}{|c|}{$\begin{array}{l}\text { Hip max. } \\
(\mathrm{Cm})\end{array}$} & \multicolumn{2}{|l|}{ MM } & \multicolumn{2}{|l|}{ BM } & \multicolumn{2}{|l|}{ WHR } & \multicolumn{2}{|l|}{ BMI } & \multicolumn{2}{|l|}{ RM } & \multicolumn{2}{|c|}{$\mathrm{BF}$} \\
\hline & & & & & Pre & Post & Pre & Post & Pre & Post & Pre & Post & Pre & Post & Pre & Post & Pre & Post & Pre & Post & Pre & Post \\
\hline $\begin{array}{l}\text { Mann } \\
- \\
\text { Whitn } \\
\text { ey U }\end{array}$ & $\begin{array}{l}11.5 \\
00\end{array}$ & 12.500 & 6.000 & 3.500 & $\begin{array}{c}11.0 \\
00\end{array}$ & $\begin{array}{c}10.5 \\
00\end{array}$ & $\begin{array}{c}13.0 \\
00\end{array}$ & $\begin{array}{l}13.0 \\
00\end{array}$ & $\begin{array}{c}10.0 \\
00\end{array}$ & $\begin{array}{c}10.0 \\
00\end{array}$ & $\begin{array}{c}14.0 \\
00\end{array}$ & $\begin{array}{c}14.0 \\
00\end{array}$ & $\begin{array}{l}13.0 \\
00\end{array}$ & $\begin{array}{c}12.5 \\
00\end{array}$ & $\begin{array}{c}13.0 \\
00\end{array}$ & $\begin{array}{l}9.00 \\
0\end{array}$ & $\begin{array}{c}4.00 \\
0\end{array}$ & $\begin{array}{c}4.00 \\
0\end{array}$ & $\begin{array}{c}10.5 \\
00\end{array}$ & $\begin{array}{c}10.5 \\
00\end{array}$ & $\begin{array}{c}14.00 \\
0\end{array}$ & $\begin{array}{l}13.0 \\
00\end{array}$ \\
\hline $\begin{array}{l}\mathrm{p} \\
\text { value }\end{array}$ & .521 & .647 & .100 & .035 & $\begin{array}{r}.46 \\
5\end{array}$ & $\begin{array}{r}.41 \\
0\end{array}$ & $\begin{array}{r}.71 \\
5\end{array}$ & $\begin{array}{r}.71 \\
5\end{array}$ & $\begin{array}{r}.36 \\
1\end{array}$ & $\begin{array}{r}.36 \\
1\end{array}$ & $\begin{array}{r}.85 \\
5\end{array}$ & $\begin{array}{r}.85 \\
5\end{array}$ & $\begin{array}{r}.71 \\
5\end{array}$ & $\begin{array}{r}.64 \\
7\end{array}$ & $\begin{array}{r}.68 \\
7\end{array}$ & $\begin{array}{l}.2 \\
46\end{array}$ & $\begin{array}{r}.0 \\
45\end{array}$ & $\begin{array}{r}.0 \\
45\end{array}$ & $\begin{array}{r}.41 \\
0\end{array}$ & $\begin{array}{r}.41 \\
0\end{array}$ & $\begin{array}{r}.85 \\
5\end{array}$ & .714 \\
\hline
\end{tabular}

Table 3. The significance of differences before and after testing in

experimental and control groups

\begin{tabular}{lll} 
& $\begin{array}{l}\text { Experimental } \\
\text { p values }\end{array}$ & Control \\
Weight Post - Weight (Kg) & .066 & .593 \\
Waist minimum Post - Waist & 1.000 & 1.000 \\
$\begin{array}{l}\text { minimum (Cm) } \\
\text { Hip maximum (Cm) Post - Hip }\end{array}$ & 1.000 & 1.000 \\
maximum (Cm) & & \\
MM Post - MM & .066 & .655 \\
BM Post - BM & .581 & .109 \\
WHR Post - WHR & .102 & .655 \\
BMI Post - BMI & .066 & .593 \\
RM Post - RM & .066 & .655 \\
BF Post - BF & .144 & .465 \\
\hline
\end{tabular}



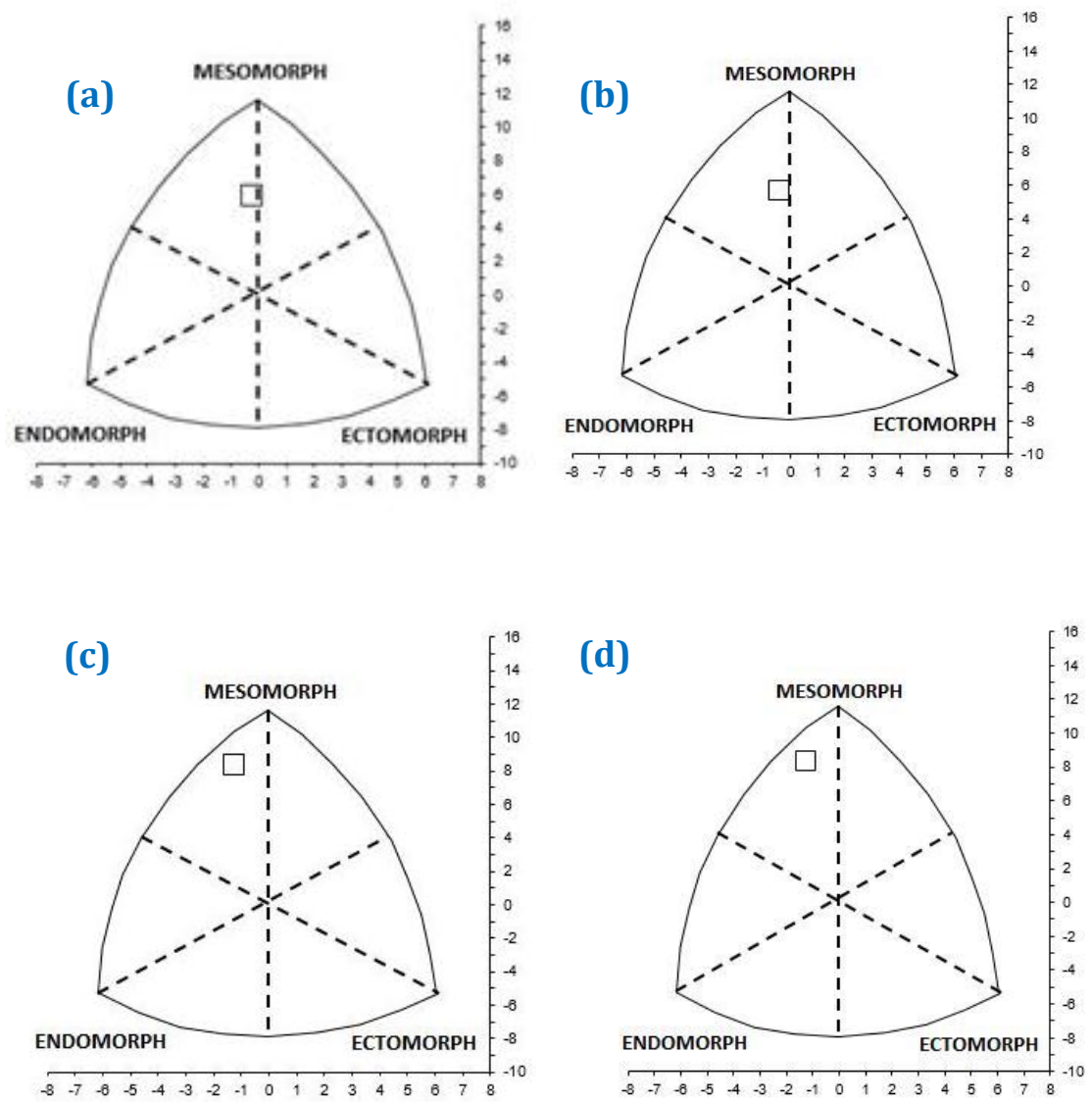

Figure 1 (a) Pre-intervention somatochart of the players in the control group (b) Post-intervention somatochart of the players in the control group (c) Pre-intervention somatochart of the players in the control group (d) Post-intervention somatochart of the players in the control group.

Mann - Whitney test revealed that there were statistically significant differences in the following parameters: ectomorfia BMI and after the training program. When we look at the median of the parameters in which it established the existence of differences between the experimental and control groups, we can conclude that the subjects in the experimental group had higher BMI before and after treatment, while the subjects in the control group are more ectomorphs Table 2.

To examine whether there are differences in body composition, measured parameters between the control and experimental groups used a Man Whitney test. The results of this test are shown in Table 2. To statistically determine whether there are differences between the examined parameters before and after treatment with the experimental and control group that used the Wilcoxon rank test or the Wilcoxon matched-pairs test. The results are shown in Table 3.
Wilcoxon rank test revealed that there were no statistically significant differences or changes in any of the measured parameters after a 6- week training program, neither in the experimental nor in the control group of patients. If necessary, the result of the experimental group can be noted, which is close to statistical significance $(p=0.07)$ and to the variables of weight, SMM, BMI and Residual mass.

In the previous figures, we can see that there has not been a statistically significant difference after the 6 - week treatment neither in the control and experimental group. Players from the control group (Figure 1 a $\&$ b) were a little more mesomorphs before and after the treatment. The players from the experimental group (Figure 1 c \& d) have been a bit further from the mesomorphs line before and after the treatment, but the somatotype of these players did not change almost at all after the treatment. On the other hand, we could say that all the players belong to the mesomorphs and that 


\section{Pantović Marko et al.,/2019}

seven weeks is not a long enough period to contribute to some somatotype changes.

\section{Discussion}

As we have already mentioned, body composition is a very important ability in almost every sports activity. It doesn't matter which sports activity is taken into account, because it is important to notice that all sports activities differ between one another, which means that body composition also differs between both player positions and sports. For instance, a high jumper body composition or somatotype significantly differs from a body composition of an elite long-distance swimmer. It is not only that fat mass and muscle mass matter, but also the residual mass, WHR, BMI, somatotype do matter with any athlete. From the previous studies, we could say that high jumpers are more ectomorphic than handball players are [11]. It is very important to notice that body composition characteristic matters in elite athletes and also in children and young athletes. Since body composition differs among high-level athletes and sports it also differs among children and young athletes [12]. Height, age of respondents, and somatotype (endomorfia, mesomorfia, ectomorphia) have remained identical during the period of the study and, therefore, cannot show measurement results after the treatment. Reviewing the table of descriptive characteristics of the variables it was noted that there had not been many changes in all variables. Our results show that there have not been significant changes in somatotype after 6 week period in which players have done complex training once a week. Also, what was expected, the height was not changed under the influence of complex training. The results also show that there haven't been any changes in the player's body composition who were in the experimental group, so we can notice that those players had a higher percentage of BMI before and after the intervention and that players from the control group are more ectomorphs than the players from the experimental group are. From the results that we have got, we can see in Table 3. That variables such as weight, BMI, $\mathrm{RM}$ and MM are closer to the statistical significance $(p=0.07)$ then to WHR, BF or BM. Still, this statistical significance is quite small. Probably this type of training program doesn't lead to some changes in all compared variables, but we could also say that frequency, volume or intensity was high enough to contribute to a very small changes in muscle mass $(p=.066)$, body mass index $(p=.066)$, residual mass $(p=.066)$ and weight $(p=.066)$. Variables such as WHR ( $\mathrm{p}=.102)$, BF $(\mathrm{p}=.144)$, BM $(\mathrm{p}=.581)$ do not show any statistically significant difference between and after the treatment. Thus, we could say that those results are not by our hypothesis in which it was argued that there would be some changes in body composition after 6-week program. We can assume that training session frequency in terms of numbers of the session, that the experimental group was performing during 6 weeks, was not enough to cause changes in body composition and somatotype in elite handball players. This program would have influenced abilities such as muscle endurance, muscle strength and explosive power [13], but for body composition changes it probably would not be enough. We could notice that there are statistically significant differences in the following parameters: somatotype (ectomorfia) and BMI after the training program. Small changes in (BMI, weight, RM, MM) that we can see in table 4 might have happened due to the weight changes during the training program. All of the above-mentioned variables, except for muscle mass, include weight values in their equations and we could assume that the weight has influenced body mass index and residual mass. However, variables that do not show the statistical significant difference after the program did not include weight in their formulas, and therefore, if we take this information into account, we can say that variables and parameters that include weight in their equations were changed and the other ones were not. All the other variables (FM, BM, somatotypes) have used equations that differ from each other, and therefore there is no particular part of an equation for which could be said that influenced another one. Only fat mass and endomorphy equations had just one part of their equations in common and that was the skinfold site (triceps). If we take into account some previous studies we can say that muscle mass and body mass (weight) does not play that important role in 


\section{Pantović Marko et al.,/2019}

handball teams or, on the other hand, these parameters are not the main ones that determine whether players or teams will be successful or unsuccessful while it was shown that teams whose players have had lower fat mass percentage were more successful [14]. Since we have got the results that show that there were small changes in body mass (weight) and muscle mass. we should say that, according to the previous study [14], it doesn't matter that much that some other parameters, such as fat mass do matter more than the other ones. Small changes in (BMI, weight, RM, MM) that we can see in table 4. might have happened due to weight changes during the training program. All of the above-mentioned variables except muscle mass include weight values in their equations and we could assume that weight has influenced body mass index and residual mass. However, variables that do not show the statistically significant difference after the program did not include weight in their formulas and, therefore, if we take this information into account we can say that variables and parameters that include weight in their equations were changed and the other ones were not. All the other variables (FM, BM, somatotypes) have used equations that differ from each other and therefore there is no particular part of an equation for which could be said that influenced other ones. Since we got results that show that there were small changes in body mass (weight) and muscle mass we should note that, according to the previous study [14], it doesn't matter so much, and that some other parameters such as fat mass, do matter more than the other ones. Since we have already mentioned it is very important to remember that it should not be spoken only about body composition in general because the body composition in handball players differs from position to position. Since there are four positions in handball (backcourt players, pivots, wings, goalkeepers) we can say that pivots cannot have the same fat or muscle mass as wings possess, or as backcourt players can have [2]. Since this study was done on elite handball players which are considered high-level athletes it has its limitations. The toosmall sample could be one of the limitations as well as the selected load for the players in the experimental group. Also, duration and frequency might have had an influence taking into account that the players have done complex training sessions once a week during the 6 weeks. Further studies should be developed on how complex training affects body composition in handball players paying attention to the limitations that this study has had.

\section{Conclusions}

There are a lot of studies written on body composition in handball players. On the other hand, very few of them have been done under the influence of complex training. Since the objective of this study was to determine whether complex training influences body composition we can conclude that there have not been statistically significant differences in the experimental group after the 6week training session. This could have happened due to the simple size (number of players involved in the study) or due to the frequency and short period under what the players have gone the program. Body composition matters also between positions so we should pay more attention to this detail. Therefore, body composition changes under the complex training influence should be further researched.

\section{References}

[1] S.C. Povoas, A.A. Ascensao, J. Magalhaes, A.F. Seabra, P. Krustrup, J.M. Soares, A.N. Rebelo, Physiological demands of elite team handball with special reference to playing position, Journal of Strength and Conditioning Research, 28 (2014) 430-442.

[2] P.T. Nikolaidis, J. Ingebrigtsen, Physical and physiological characteristics of elite male handball players from teams with a different ranking, Journal of Human Kinetics, 38 (2013) 115-124.

[3] S. Pavlović, M. Talović, E. Kazazović, R. Lakota, Analysis and Differences in the Basic Motor and Situational Motor Abilities between Female Handball Players in the Bih First Federal League and the First League of the Republika Srpska, Sportlogia, 9 (2013) 129-133.

[4] A. Martinez-Rodriguez, E. Roche Collado, N. Vicente-Salar, Body composition assessment of paddle and tennis adult male players, Nutricion 
Hospitalaria, 31 (2015) 1294-1301.

[5] Kevin Norton, Michaell Marfell-Jones, Nansy Whittingham, Deborah Kerr, Lindsay Carter, Kaylene Saddington, et al. Anthropometric Assessment Protocols. In: Gore CJ, editor. Physiological Test for Elite Athletes 2000.

[6] H. Ghobadi, H. Rajabi, B. Farzad, M. Bayati, I. Jeffreys, Anthropometry of World-Class Elite Handball Players According to the Playing Position: Reports From Men's Handball World Championship 2013, Journal of Human Kinetics, 39 (2013) 213-220.

[7] V. Srhoj, M. Marinović, N. Rogulj, Position Specific Morphological Characteristics of TopLevel Male Handball Players, Journal of the Croatian Anthropological Society, 26 (2002) 219-27.

[8] G.G. Haff, N.T. Triplett, Exercise Technique for Free Weight and Machine Training. In: S. Caulfield, Berninger. D, editors. Essentials of Strength Training and Conditioning Human Kinetics; 2016. p. 352.

[9] M. Marfell-Jones, A. Stewart, T. Olds, Kinanthropometry IX $1^{\text {st }}$ ed. London: Routledge; 2006.

[10] R.F. Castillo, de la Rosa RJ. Relation between body mass index and bone mineral density among haemodialysis patients with chronic kidney disease, Journal of Renal Care, 35 Suppl 1 (2009) 57-64.

[11] P.A. KaurTiwana, Comparative Study of Anthropometric Measurements, Physique and Body Composition of Intervarsity level Jumper Girls, International Journal of Scientific and Research Publications, 3 (2004) 186-193.

[12] J.M. János Mészáros, T. Szabó, I. Szmodis, Anthropometry and competitive sport in Hungary, Acta Biologica Szegediensis, 44 (2000) 189-192.

[13] D.N.G. Nandakumar, Impact of Plyometric Training and Complex Training on Selected Physical Fitness Variables in College Men's Handball, International Research Journal of Multidisciplinary Science \& Technology, 1 (2016) 129-131.

[14] A.A.A. Hasan, J.A. Rahaman, N.T. Cable, T.
Reilly, Anthropometric profile of Elite Male Handball Players in Asia, Biology of Sport, 24 (2007) 3-12. 
Pantović Marko et al.,/2019

Funding

This study was not funded by any grant

Acknowledgments

The authors would like to thank every participant for his effort and time.

\section{Conflict of interest}

None of the authors have any conflicts of interest to declare.

Informed consent

All participants gave written informed consent to participate in this study.

\section{About the License}

\section{(C) (1)}

Attribution 4.0 International (CC BY 4.0)
The text of this article is licensed under a Creative Commons Attribution 4.0 International License 